\title{
Influence of Hydrogen-Bonding Interactions on Nuclearity and Structure of Palladium Tiara-like Complexes
}

\author{
Harry J. Martin, Constance R. Pfeiffer, E. Stephen Davies, Adrienne L. Davis, William Lewis, ${ }^{\circledR}$ \\ and Neil R. Champness*(1)
}

School of Chemistry, University of Nottingham, University Park, Nottingham NG7 2RD, U.K.

\section{Supporting Information}

ABSTRACT: The role of intramolecular hydrogen-bonding interactions upon the nuclearity of palladium tiara-like complexes is reported herein. The synthesis of three palladium tiaras is described with three related thiolate ligands that vary in their hydrogen-bonding capability, amide vs ester for $\mathrm{N}$ acetylcysteamine (tiara $\mathbf{1}$ ) vs 2 -mercaptoethyl acetate (tiara 2 ) or ethyl thioglycolate (tiara 3 ), and in the relative position of the ester group, 2-mercaptoethyl acetate (2) or ethyl thioglycolate (3). Mass spectrometry indicates that, in the absence of protic solvents, $\mathrm{N}$-acetylcysteamine reacts to form exclusively a six-membered tiara, [ $\mathrm{Pd}$ $\left.\left(\mathrm{SCH}_{2} \mathrm{CH}_{2} \mathrm{NHCOCH}_{3}\right)_{2}\right]_{6}, \mathbf{1}$, whereas the ester containing analogues form both six- and eight-membered tiaras. Single-
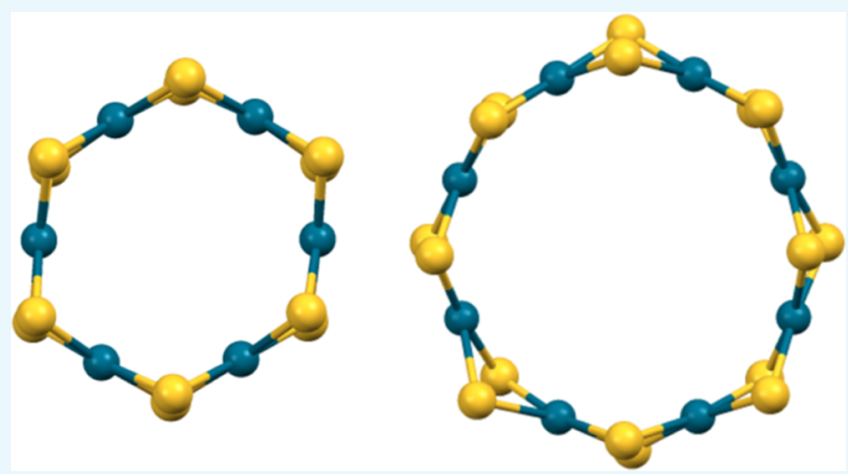
crystal X-ray diffraction studies indicate the significance of intramolecular $\mathrm{N}-\mathrm{H} \cdots \mathrm{O}$ hydrogen bonds in determining the nuclearity of the amide-containing tiara $\mathbf{1}$. NMR studies indicate that $\mathbf{1}$ is not in equilibrium with larger tiaras in solution, and that the smaller size of the aggregate inhibits the fluxional behavior of the pendant thiolate ligands, typically observed for larger tiaras. Electrochemical investigations of 1 reveal reductive processes that exhibit an increase in current upon addition of acid, along with the formation of palladium nanoparticles.

\section{INTRODUCTION}

In recent years, toroidal, or tiara-like, metal complexes have received wide attention due to their fascinating structures and diverse and unusual properties. ${ }^{1}$ Among the many possible approaches to synthesizing such structures, metal-thiolate complexes are attractive targets due to the strong nature of many $\mathrm{M}-\mathrm{S}$ bonds and the ability of thiolates to act as bridges between metal centers. Additionally, metal-thiolates have been studied widely in part due to their relevance to bioinorganic chemistry and their central role in several key enzymes. ${ }^{2}$

Although a variety of metals have been employed to synthesize tiaras, including molybdenum, ${ }^{3}$ vanadium, ${ }^{4}$ iron, and cobalt, ${ }^{5}$ one family of metal-thiolate-based tiaras that have received particular attention are those based on Group 10 metals, $\left[\mathrm{M}(\mathrm{SR})_{2}\right]_{n}$, where $\mathrm{M}=\mathrm{Ni}, \mathrm{Pd}$, or $\mathrm{Pt}$ and $n$ most commonly varies from 4 to 12 , with 6 and 8 being predominant. ${ }^{6}$ In such systems, the metal cations lie in a plane and are separated by two bridging thiolate ligands that are located above and below the metal plane; the "arms" of the ligands extend away from the ring, or occasionally in the case of larger tiaras, fill the central void. ${ }^{7,8}$ The stability of these complexes derives strongly from the $\mathrm{M}-\mathrm{S} \pi$-bonds. ${ }^{9}$ This is evidenced by the limited examples of tiara-like complexes with an odd number of metals, where the resulting structure has a mismatch of overlapping orbitals. ${ }^{9}$ Along with their catalytic activity for water reduction, ${ }^{10,11}$ tiara-like complexes have been shown to demonstrate nonlinear optical properties, ${ }^{1}$ limited host-guest chemistry, ${ }^{7,12,13}$ and suitability as a precursor to monodisperse nanoparticles. ${ }^{14}$

It is clearly important to be able to control the nuclearity of such tiaras, as it can be readily envisaged that the resulting size of the aggregates will have a significant bearing upon the properties of the complexes. Although there exists an overwhelming abundance of hexanuclear nickel and palladium tiaras reported in the literature, there is considerable variety in the structures of the published complexes and tiaras with sizes up to $\mathrm{Pd}_{20}$ recently reported. ${ }^{15}$ Modification of the thiolate ligands adds further diversity to the complexes reported, particularly in the cases of multiligand complexes. ${ }^{1,2,12,16}$ Thus, in this study, we report the influence of ligand functionality on the nuclearity of such complexes and demonstrate that through the incorporation of hydrogen-bonding capability, in the form of amide groups, it is possible to significantly influence the nuclearity of the resulting $\left[\mathrm{Pd}(\mathrm{SR})_{2}\right]_{n}$ tiara complexes.

Received: May 25, 2018

Accepted: July 25, 2018

Published: August 8, 2018 


\section{RESULTS AND DISCUSSION}

Complexes 1-3 were successfully synthesized by reaction of $\mathrm{PdCl}_{2}$ with $\mathrm{N}$-acetylcysteamine (tiara 1), 2-mercaptoethyl acetate (tiara 2), or ethyl thioglycolate (tiara 3) (Figure 1) in<smiles>CCOC(=O)CS</smiles>

Figure 1. Thiol ligands employed in the synthesis of tiaras in this study.

the presence of a base. The ligands were chosen, as they vary only in their ability to form hydrogen bonds, $\mathrm{N}$-acetylcysteamine containing an amide in contrast to the ester group of 2mercaptoethyl acetate, or in the position of the ester in ethyl thioglycolate in comparison to 2-mercaptoethyl acetate. The samples were characterized by spectroscopic methods, IR, $\mathrm{UV}-$ vis, and ${ }^{1} \mathrm{H} \mathrm{NMR}$, and by matrix-assisted laser desorption ionization time-of-flight (MALDI-TOF) mass spectrometry. The latter provided valuable insight into the nuclearity of the resulting products.

MALDI-TOF mass spectrometry is helpful in determining the nuclearity of the tiara complexes from each reaction. Reaction of $\mathrm{PdCl}_{2}$ with $\mathrm{N}$-acetylcysteamine $\left(\mathrm{L}_{1}\right)$, using $\mathrm{N}, \mathrm{N}$ diisopropylethylamine as a base, in different solvents (tetrahydrofuran (THF), $n$-PrOH, EtOH, and $\mathrm{MeOH}$ ) leads to products of different nuclearity (Figure 2). When using THF as solvent, exclusively six-membered tiaras, $\left[\mathrm{Pd}\left(\mathrm{L}_{1}\right)_{2}\right]_{6}, \mathbf{1}$,

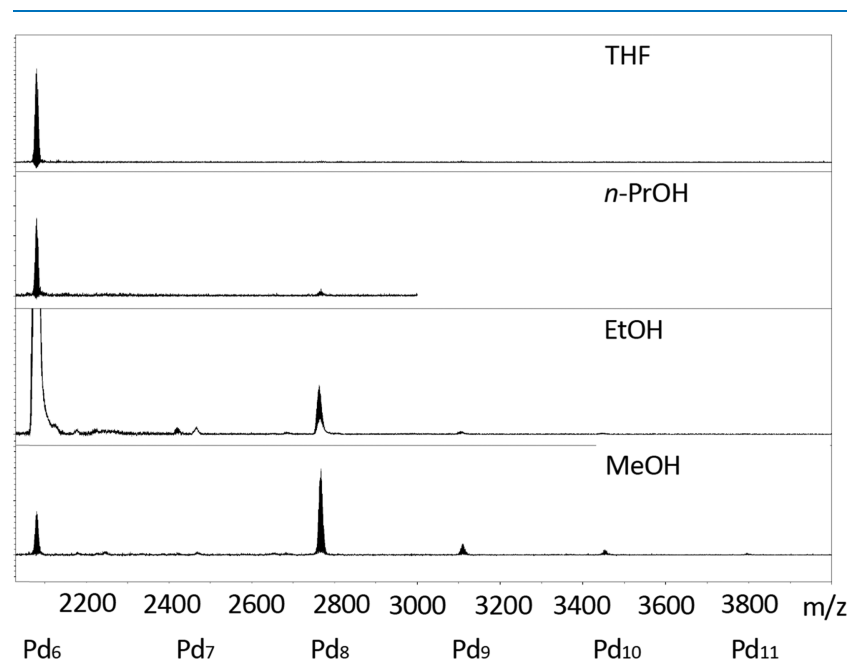

Figure 2. MALDI-TOF mass spectra of tiara products generated from the reaction of $\mathrm{N}$-acetylcysteamine with $\mathrm{PdCl}_{2}$, using $\mathrm{N}, \mathrm{N}$ diisopropylethylamine as a base, in different solvents (from top to bottom) THF, $n-\mathrm{PrOH}, \mathrm{EtOH}$, and $\mathrm{MeOH}$. See Figure S1 for mass spectrum of 1 in THF between $\mathrm{m} / z 0$ and 4000, which confirms the presence of only the hexanuclear tiara. For a comparison of experimental and calculated isotopic distributions, see Figure S2. are formed. In alcoholic solvents, significant proportions of eight-membered tiaras are also observed and, in the case of $\mathrm{EtOH}$ and $\mathrm{MeOH}$, masses corresponding to seven- and ninemembered tiaras are observed. When $\mathrm{MeOH}$ was used as solvent, a large range of different nuclearities are observed, ranging from six-membered, $\left[\mathrm{Pd}\left(\mathrm{L}_{1}\right)_{2}\right]_{6}$, to eleven-membered, $\left[\mathrm{Pd}\left(\mathrm{L}_{1}\right)_{2}\right]_{11}$, although some of these species may be due to fragmentation during the mass spectrometry experiment.

Due to the success in producing solely six-membered tiaras when using THF as the reaction solvent for the synthesis of $\mathbf{1}$, we expanded our study to investigate the synthesis of related tiaras 2, using 2-mercaptoethyl acetate $\left(\mathrm{L}_{2}\right)$, and 3, employing ethyl thioglycolate $\left(\mathrm{L}_{3}\right)$ as ligand. Characterization by MALDITOF mass spectrometry reveals that whereas 1 forms exclusively six-membered tiaras, $\left[\mathrm{Pd}\left(\mathrm{L}_{1}\right)_{2}\right]_{6}, 2$ forms both sixand eight-membered, $\left[\mathrm{Pd}\left(\mathrm{L}_{2}\right)_{2}\right]_{8}$, tiaras and 3 forms only eightmembered tiaras (Figure 3 ). If the nuclearity of the tiara was

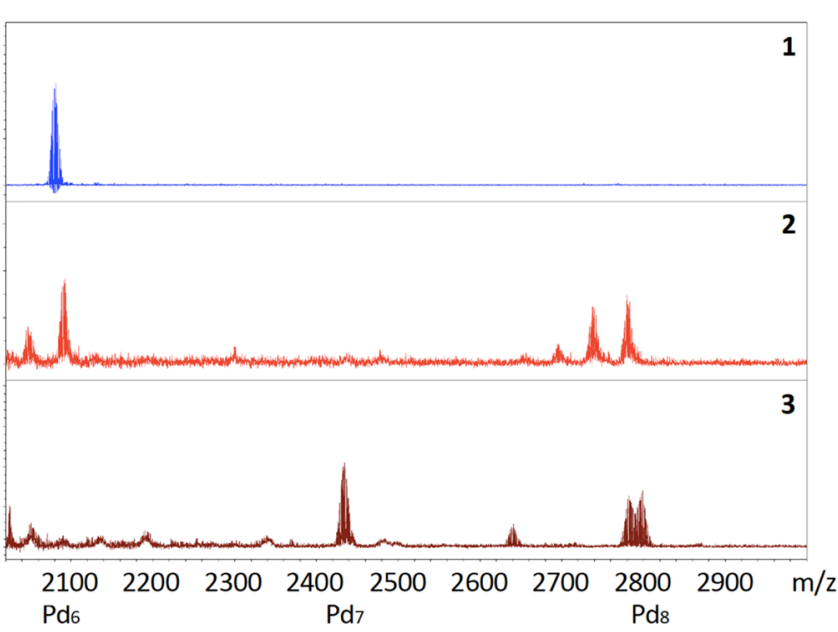

Figure 3. MALDI-TOF mass spectra of tiara products generated from the synthesis in THF of $\mathbf{1}$ (top, blue), $\mathbf{2}$ (red, middle), and $\mathbf{3}$ (maroon, bottom) illustrating the different tiara nuclearities observed in each case. For comparison of experimental and calculated isotopic distributions, see Figures S2-S4.

determined simply by ligand length and steric profile, then $\mathbf{1}$ and 2 would be expected to behave similarly. Previous studies have reported that methyl thioglycolate reacts with $\mathrm{PdCl}_{2}$ to form exclusively octanuclear tiaras ${ }^{6}$ and therefore the behavior of 3, which employs a ligand of similar sterics to methyl thioglycolate (the ligand is simply slightly longer) is less surprising. Interestingly, our studies demonstrate that the reaction solvent has some role to play in the synthesis of $\mathbf{1}$. If THF is replaced by a protic alcohol solvent, such as $n$ propanol, then a small peak corresponding to the octanuclear tiara $\left[\mathrm{Pd}\left(\mathrm{SCH}_{2} \mathrm{CH}_{2} \mathrm{NHCOCH}_{3}\right)_{2}\right]_{8}$ is observed. On proceeding from $n$-propanol to ethanol and then to methanol, the proportion of the eight-membered tiara is observed to increase in relation to the proportion of the hexanuclear tiara.

For all three compounds, 1, 2, and 3, single crystals were successfully grown by slow evaporation of solutions of the compounds in $\mathrm{MeOH}(\mathbf{1})$ or $\mathrm{CHCl}_{3}(2,3)$ and the structure of the compounds was determined by X-ray diffraction analysis. For 1 and 2 hexagonal and for 3 octagonal tiara structures were observed. In the cases of $\mathbf{1}$ and 3 , this is consistent with the mass spectrometry data discussed above. However, for 2, only single crystals of the hexanuclear tiara 

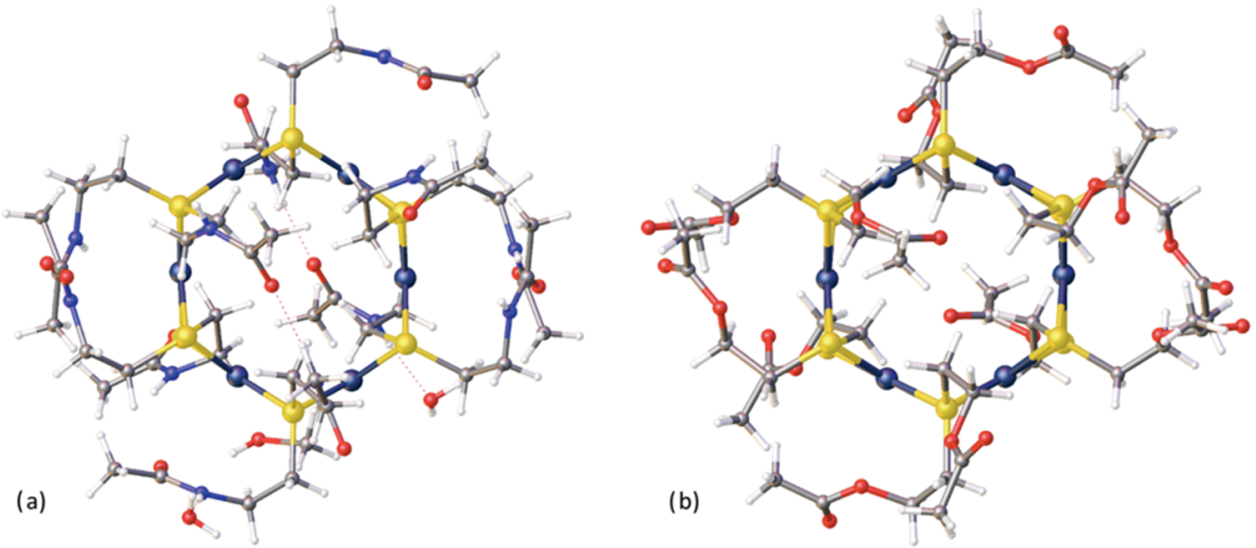

Figure 4. Views of (a) 1 and (b) 2 perpendicular to the plane of the tiara $\mathrm{Pd}_{6}$ hexagon. For (1) $\mathrm{Pd}-\mathrm{S}$ bond lengths vary from $2.3169(5)$ to 2.3482(5) $\AA$, average $2.33 \AA$; $\mathrm{Pd}-\mathrm{S}-\mathrm{Pd}$ angles exhibit an average of $83.8^{\circ}$ and $\mathrm{S}-\mathrm{Pd}-\mathrm{S}$ angles an average of $97.9^{\circ}$. For $(2) \mathrm{Pd}-\mathrm{S}$ bond lengths vary from $2.3099(9)$ to $2.3351(10) \AA$, average $2.33 \AA$; Pd-S-Pd angles exhibit an average of $83.4^{\circ}$ and $\mathrm{S}-\mathrm{Pd}-\mathrm{S}$ angles an average of $93.9^{\circ}$. Pd, dark blue; S, yellow; O, red; N, light blue; C, gray; $\mathrm{H}$, white.

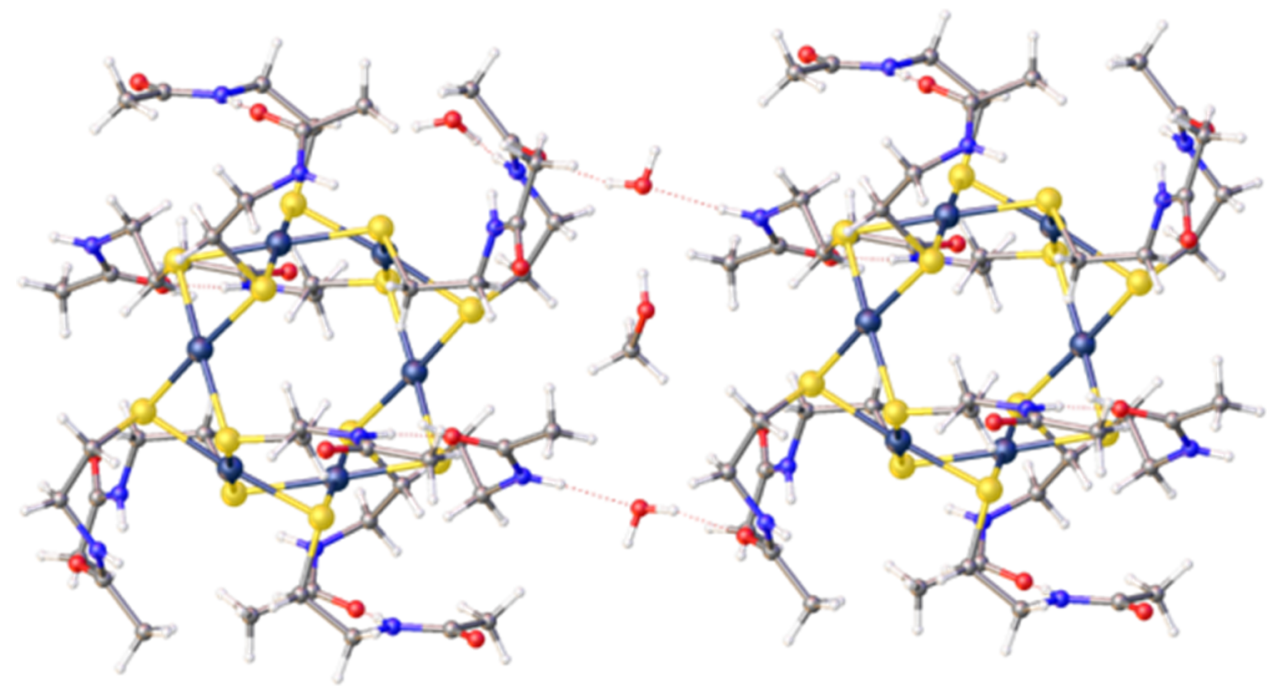

Figure 5. View of the hydrogen-bonding interactions adopted between 1 and water molecules that bridge adjacent tiaras. A MeOH solvent molecule is accommodated in the pocket formed between adjacent tiaras. Hydrogen bonds between amides and water molecules are illustrated by dotted lines $\left(\mathrm{N} \cdots \mathrm{O}=2.865(3) \AA ̊ . ;>\mathrm{N}-\mathrm{H} \cdots \mathrm{O}=164^{\circ} ; \mathrm{N} \cdots \mathrm{O}=3.027(2) \AA ̊ . ;>\mathrm{N}-\mathrm{H} \cdots \mathrm{O}=175^{\circ}\right)$.

were isolated, despite this being the minor product identified in the MALDI-TOF spectrum.

The compound $\mathbf{1}$ was found to co-crystallize as a hydrate, with four water molecules per tiara along with a molecule of the crystallization solvent, methanol $\left(1 \cdot 4 \mathrm{H}_{2} \mathrm{O} \cdot \mathrm{MeOH}\right)$, whereas $\mathbf{2}$ or $\mathbf{3}$ do not form a solvate under the conditions used for crystallization. The solid-state structure of both $\mathbf{1}$ and 2 confirm the conventional tiara arrangement with each $\mathrm{Pd}(\mathrm{II})$ cation bridged through $\mu^{2}$-S thiolate donors to adjacent metal cations in a hexagonal ring (Figure 4). Whereas 2 forms a nearperfect $\mathrm{Pd}_{6}$ hexagon ( $>\mathrm{Pd}-\mathrm{Pd}-\mathrm{Pd}=119.28(2), 119.75(2)$, and $120.96(2)^{\circ}$ ) (Figure $4 \mathrm{~b}$ ), distortion of the corresponding angles $\left(>\mathrm{Pd}-\mathrm{Pd}-\mathrm{Pd}=115.49(2), 120.71(2)\right.$, and $\left.123.80(2)^{\circ}\right)$ in 1 leads to significant distortion from the idealized symmetrical hexagon (Figure $4 \mathrm{a}$ ). Comparison of the crosstiara $\mathrm{Pd}-\mathrm{Pd}$ distances reveal the distortion of the $\mathrm{Pd}_{6}$ hexagon in 1. Thus, the shortest and longest opposing $\mathrm{Pd}-\mathrm{Pd}$ distances are 6.0140(2) and 6.4592(3) $\AA$ (average distance 6.217 $\AA$ ) for 1 in comparison to 6.1366(5) and 6.2382(5) $\AA$ (average 6.194 A) for 2, respectively. As expected, the distances between adjacent $\mathrm{Pd}$ atoms around the tiara hexagon are similar in both cases; ranging from $3.0598(2)$ to $3.1730(2) \AA$ (average $3.11 \AA$ ) for 1 and 3.0722(3) to 3.1179(4) $\AA$ (average 3.10 $\AA$ ) for 2 .

The main difference between the X-ray structures of 1 and 2 results from the hydrogen-bonding capability of the amidecontaining $\mathrm{N}$-acetylcysteamine ligands. Both intra- and intermolecular (tiara- $\mathrm{H}_{2} \mathrm{O}$ ) hydrogen-bonding interactions are observed. Within each tiara, six thiolate ligands are bound to each face of the tiara. Of these, three adopt an orientation such that the tail of the ligand is arranged approximately perpendicular with respect to the $\mathrm{Pd}_{6}$ plane, whereas the other three are approximately parallel to the plane. The perpendicular and parallel orientated ligands are arranged alternately around the tiara, a feature also observed by NMR spectroscopy, see below. A complex arrangement of the intramolecular $\mathrm{N}-\mathrm{H} \cdots \mathrm{O}$ hydrogen bonds between adjacent amide groups exist between ligands that are perpendicular to the plane of the tiara $\left(\mathrm{N} \cdots \mathrm{O}=2.836(3) \AA \AA^{\prime} ; \mathrm{N}-\mathrm{H} \cdots \mathrm{O}=\right.$ $\left.169^{\circ}\right)$, ligands that are parallel to the plane of the tiara $(\mathrm{N} \cdots \mathrm{O}$ $\left.=2.901(2) \AA ;>\mathrm{N}-\mathrm{H} \cdots \mathrm{O}=168^{\circ}\right)$, and between perpendicular and parallel oriented ligands $(\mathrm{N} \cdots \mathrm{O}=2.872(2) \AA ; ; \mathrm{N}-\mathrm{H} \cdots \mathrm{O}$ $\left.=135^{\circ}\right)$. The compound 1 co-crystallizes with water molecules, 


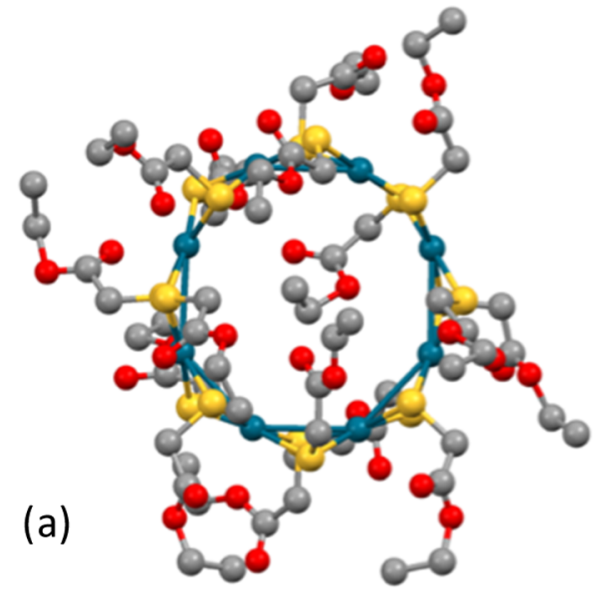

(b)

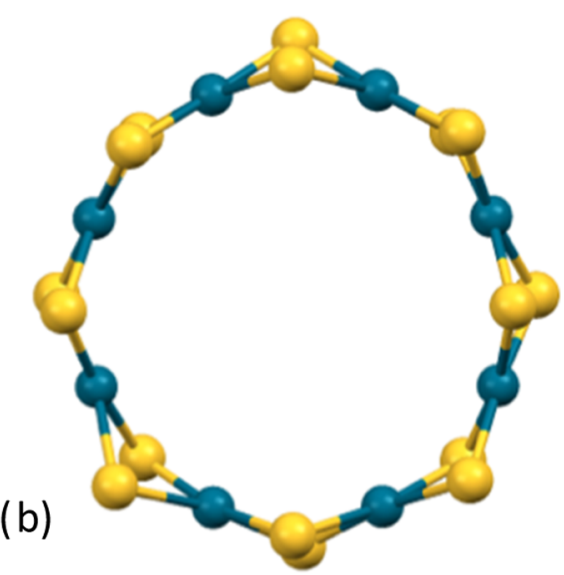

Figure 6. Views perpendicular to the plane of the tiara $\mathrm{Pd}_{8}$ octagon in 3. In (a) and (b), hydrogen atoms and ethyl thioglycolate ligands have been omitted for clarity, respectively. The Pd-S bond lengths vary from 2.296(2) to 2.352(9) A, average $2.32 \AA$; $\mathrm{Pd}-\mathrm{S}-\mathrm{Pd}$ angles exhibit an average of $88.4^{\circ}$ and $\mathrm{S}-\mathrm{Pd}-\mathrm{S}$ angles an average of $90.3^{\circ}$. Pd, dark blue; $\mathrm{S}$, yellow; $\mathrm{O}$, red; $\mathrm{N}$, light blue; $\mathrm{C}$, gray.

which participate in hydrogen-bonding interactions with the ligand amide groups. One such water molecule acts as a bridge between adjacent tiara molecules, forming a pocket that accommodates a molecule of $\mathrm{MeOH}$ that adopts hydrogen bonds to the water molecules (Figure 5).

The crystal structure of 3 confirms the $\mathrm{Pd}_{8}$ tiara, as suggested by the mass spectrometry studies. The structure was found to exhibit a dynamic disorder in the positions of the ligand arms, which is perhaps consistent with the absence of strong interactions, such as hydrogen bonds, between adjacent ligands. The $\mathrm{Pd}_{8}$ octagon is distorted (Figure 6) such that the $>\mathrm{Pd}-\mathrm{Pd}-\mathrm{Pd}$ angles range from $130.38(2)$ to $140.21(2)^{\circ}$ (in comparison to the idealized angle of $135^{\circ}$ ). Similarly to the distortion in $\mathbf{1}$, the cross-tiara $\mathrm{Pd}-\mathrm{Pd}$ distances reveal the distortion of the octagon with the $\mathrm{Pd}-\mathrm{Pd}$ distances ranging from $8.2457(8)$ to $8.6039(9) \AA$ (average distance $=8.436 \AA$ ). The distances between adjacent $\mathrm{Pd}$ atoms around the tiara octagon range from $3.1694(6)$ to $3.2741(6)$ A. An average Pd-Pd separation of $3.23 \AA$ is observed, significantly longer than the same separations in both $1(3.11 \AA)$ and 2 (3.10 $)$. It is, however, consistent with the analogous separations in octagonal tiara with methyl thioglycolate ligands (3.23(4) A). ${ }^{8}$ We conclude that with no significant intra- or intermolecular interactions, the ethyl thioglycolate does not have a significant role in determining the overall structure.

We were interested in investigating whether the amideamide hydrogen-bonding interactions in $\mathbf{1}$ persist in solution and whether any intermolecular aggregation of tiaras could be observed. The ${ }^{1} \mathrm{H}$ NMR spectrum in $\mathrm{CD}_{3} \mathrm{OD}$ of $\mathbf{1}$ displays six distinct shifts in the NMR spectrum consistent with the axial and equatorial $\alpha-\mathrm{CH}_{2}, \beta-\mathrm{CH}_{2}$, and $\mathrm{CH}_{3}$ groups of the ligands being inequivalent, as has been observed previously for related complexes. ${ }^{5}$ Unfortunately, the signal due to the amide proton could not be located, presumably due to exchange with the $\mathrm{CD}_{3} \mathrm{OD}$ solvent, and the tiara was found to be only sparingly soluble in nonprotic solvents. Dilution experiments were performed to investigate aggregation effects, but no changes in the NMR spectrum were observed. ${ }^{1} \mathrm{H}$ NMR spectra of $\mathbf{2}$ and 3 similarly show no evidence of aggregation, as expected for these nonhydrogen-bonding systems.

The structures of the tiara complexes were explored further by two-dimensional (2D) NMR spectroscopy. As compound 2 forms both six- and eight-membered tiaras, detailed NMR experiments were not pursued further. The previously reported nature of the nonequivalency of the axial and equatorial ligands in tiara complexes ${ }^{8}$ encouraged us to further investigate the ${ }^{1} \mathrm{H}$ NMR spectra of $\mathbf{1}$ and $\mathbf{3}$ by correlation spectroscopy (COSY) experiments. Due to solubility differences, spectra for 1 were recorded in $\mathrm{CD}_{3} \mathrm{OD}$ and those for 3 in $\mathrm{CDCl}_{3}$. The ${ }^{1} \mathrm{H} \mathrm{COSY}$ spectrum of 1 (see the Supporting Information (SI), Figure S1) shows a correlation between the triplets at 3.57 and 2.67 ppm and those at 3.44 and $2.58 \mathrm{ppm}$, corresponding to the nonequivalent axial and equatorial ligands, respectively. No coupling is seen between axial and equatorial protons. Additionally, a weak coupling is observed between the triplets at $3.57 / 3.44 \mathrm{ppm}$ and singlets at $2.02 / 1.98 \mathrm{ppm}$ (see the SI). This represents a long-range scalar coupling between the $\beta$ $\mathrm{CH}_{2}$ and terminal $\mathrm{CH}_{3}$ groups on the ligand arms, possibly enhanced by the character of the amide bond; however, this could also arise from a favorable conformation of the ligand thiolate arms resulting from the intramolecular hydrogen bonding in the solution. ${ }^{1} \mathrm{H}$ COSY NMR for 3 similarly reveals coupling between $\beta-\mathrm{CH}_{2}$ protons and terminal $\mathrm{CH}_{3}$ protons, but no longer-range coupling is observed in this case, even between the $\alpha-\mathrm{CH}_{2}$ and the $\beta-\mathrm{CH}_{2}$ protons, possibly due to the replacement of the amide functionality.

The nuclear Overhauser enhancement spectroscopy (NOESY) spectrum of 3 (see the SI, Figure S4) shows cross peaks of the same sign as the diagonal arising between the axial and equatorial signals. Such signals could arise from either a true through-space interaction or from chemical exchange; in this case arising from sulfur inversion and axial to equatorial orientation of the ligand, and vice versa. A weak signal arising between the quartets and the triplets in the spectrum is also observed. This signal exhibits an opposing sign to the diagonal, implying a difference in the nature of the interaction and further indicating that chemical exchange is the origin behind the cross peaks seen between the axial and equatorial signals. As the nature of the origin of cross peaks seen between the axial/equatorial signals could not be unequivocally determined by the NOESY experiment, ROESY spectroscopy was employed, as cross peaks resulting from through-space interactions in a ROESY spectrum (see the SI, Figure S5) exhibit the opposite sign to the diagonal. The same-sign correlations obtained indicate that the two sets of resonances undergo exchange in the solution, confirming the axial/ 
equatorial nature of the nonequivalent proton signals. Opposite-sign cross peaks are also observed between the quartet at $4.24 \mathrm{ppm}$ and the triplet at $1.34 \mathrm{ppm}$, along with a correlation between the quartet at $4.44 \mathrm{ppm}$ and the singlet at $3.39 \mathrm{ppm}$. These are likely to result from the through-space interactions between the $\beta-\mathrm{CH}_{2}$ and terminal $\mathrm{CH}_{3}$ protons via the nuclear Overhauser effect (NOE) rather than chemical exchange.

In contrast, the NOESY spectrum of $\mathbf{1}$ (see the SI, Figure S2) does not show chemical exchange arising between the axial/equatorial pairs of signals. Whereas 3 possesses an ester group and no strong intramolecular interactions, the amide in complex 1 possesses the capability for strong intramolecular hydrogen-bonding interactions, inhibiting axial/equatorial ligand exchange. It should be noted that the spectra for 3 were recorded in $\mathrm{CDCl}_{3}$ solutions, precluding strong solventcomplex interactions, whereas the spectra for 1 were recorded in $\mathrm{CD}_{3} \mathrm{OD}$, which is capable of participating in hydrogen bonding, potentially inhibiting ligand inversion due to $\mathrm{CD}_{3} \mathrm{OD} \cdots 1$ intermolecular interactions. The spectrum does, however, continue to show a weak correlation between the signals observed for the $\alpha-\mathrm{CH}_{2}$ and the $\beta-\mathrm{CH}_{2}$ protons, indicating that a through-space interaction continues to be observed. It should be noted that the interaction may arise from a close spatial configuration between protons located on different ligands on the same tiara.

Variable temperature experiments were employed to further examine the ligand configuration in 1 and 3 (Figure 7). The ${ }^{1} \mathrm{H}$ NMR spectrum of 3 , recorded at $298 \mathrm{~K}$ in $\mathrm{CD}_{3} \mathrm{CN}$, reveals a broadening of the signals observed for the $\beta-\mathrm{CH}_{2}$ environments and the $\mathrm{CH}_{3}$ protons, for only one of the two ligand configurations. On increasing the experiment temperature from 298 to $338 \mathrm{~K}$, the sharper signals at 4.24 and 1.34 ppm broaden independently. On decreasing the temperature of the experiment from 298 to $263 \mathrm{~K}$, the broad signals at 4.44 and $1.56 \mathrm{ppm}$ broaden further. Previous experiments have attributed this selective line broadening to the movement of the axial ligand arm into the center of the tiara. In contrast, the variable temperature spectra of $1\left(\mathrm{CD}_{3} \mathrm{OD}\right)$ show a broadening of all the signals simultaneously on the reduction of the experiment temperature from 298 to $203 \mathrm{~K}$. This is attributed to the smaller size of the hexanuclear tiara compared to the larger octanuclear ring of 3 , preventing free movement of the axial arm into the center of the ring. The lack of asymmetrical broadening for this complex indicates the presence of a single size of tiara ring, as larger ring species would be expected to undergo selective line broadening.

Diffusion ordered spectroscopy (DOSY) was used to confirm the absence of other sized rings present in the solution. Measurements were recorded for $1\left(\mathrm{CD}_{3} \mathrm{OD}\right)$ and 3 $\left(\mathrm{CDCl}_{3}\right)$. The data obtained approximate a nominal diffusion coefficient of $3.61 \times 10^{-10} \mathrm{~m}^{2} \mathrm{~s}^{-1}$ for 1 and $4.02 \times 10^{-10} \mathrm{~m}^{2} \mathrm{~s}^{-1}$ for 3; the observation of a larger diffusion coefficient for the octanuclear ring was unexpected but rationalized by the lower viscosity of chloroform relative to methanol and the slightly larger hydrodynamic radius, calculated using the StokesEinstein equation, of $\mathbf{3}$ in comparison to $\mathbf{1}$ (9.37 vs $9.00 \mathrm{~nm}$, respectively). Comparison of the experimental data and the predicted values generated by the calculations provided by Morris et al. ${ }^{17}$ support this rationalization. It should be noted that the DOSY method suffers from several drawbacks when applied to tiara-like complexes. As these molecules contain a large number of heavy $(\mathrm{Pd}, \mathrm{S})$ atoms, their molecular weight

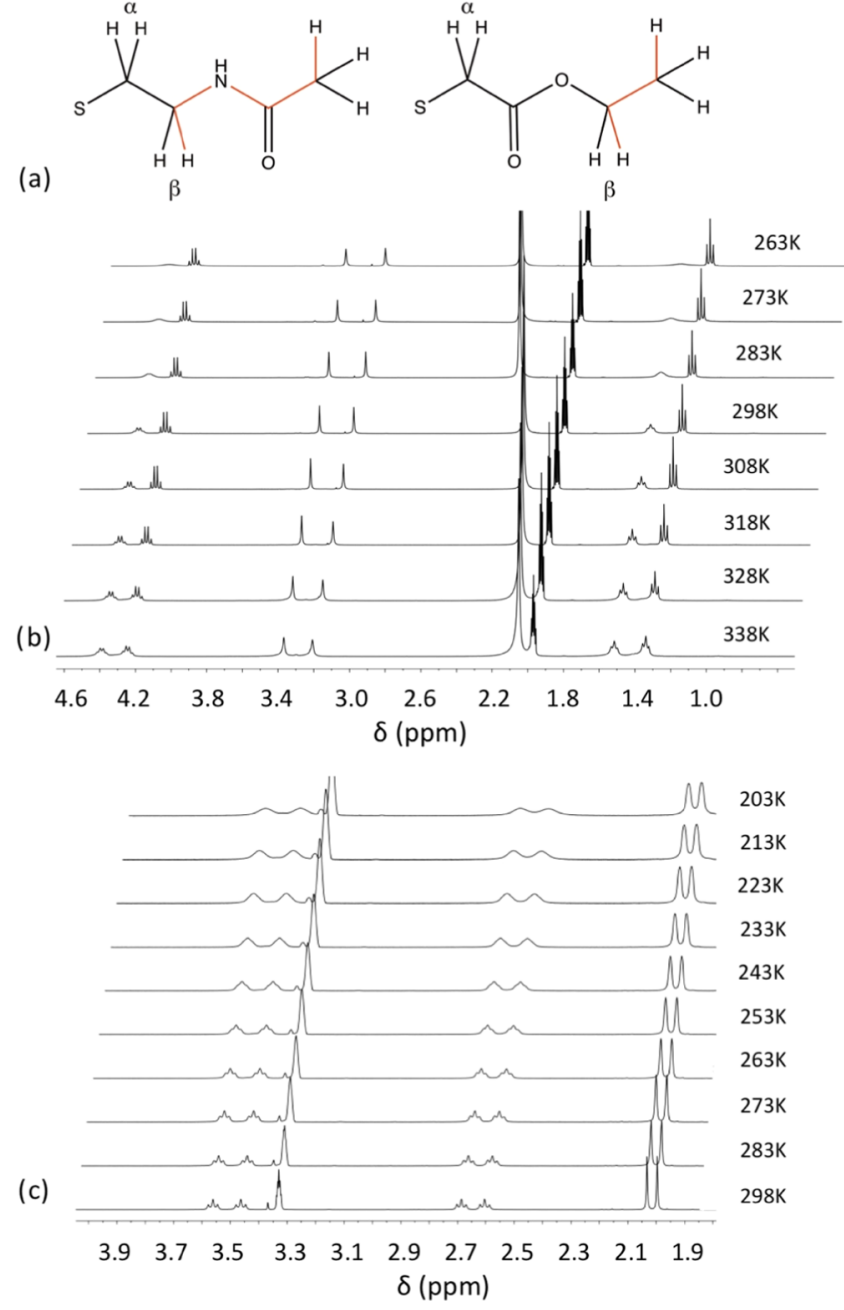

Figure 7. (a) Nomenclature employed in the description of 2D NMR spectra, scalar coupling indicated by highlighted bonds for $\mathbf{1}$ (left) and 3 (right). (b) Variable temperature ${ }^{1} \mathrm{H}$ spectrum of 3 in $\mathrm{MeCN}$ from 338 to $263 \mathrm{~K}$. (c) Variable temperature ${ }^{1} \mathrm{H}$ spectrum of 1 in $\mathrm{MeOH}$ from 298 to $203 \mathrm{~K}$. Both variable-temperature NMR experiments were performed in ten degree increments.

does not correlate to size, as organic molecules typically contain only elements lighter than sulfur. This is particularly notable when considering rings of identical composition but differing nuclearities; the molecular weight increases substantially on addition of $2\left[\mathrm{Pd}(\mathrm{SR})_{2}\right]$ units, but results in only a slight increase in the radius of the complex. However, both sets of data provide linear fits and are consistent with singlecomponent systems, indicating the absence of multiple sizes of rings in the solution phase.

The electrochemical properties of $\mathbf{1}$, alone and in the presence of either acetic acid (Figure 8) or trifluoroacetic acid (TFA) (Figure 9), were investigated as solutions in $N, N$ dimethylformaide (DMF) containing $\left[\mathrm{NBu}_{4}\right]\left[\mathrm{BF}_{4}\right](0.2 \mathrm{M})$ using cyclic voltammetric (CV) and coulometric techniques. In the absence of acid, the cyclic voltammetry of 1 shows a distinct reduction process at $E_{\mathrm{p}}{ }^{\mathrm{c}}-1.75 \mathrm{~V}$ vs $\mathrm{Fc}^{+} / \mathrm{Fc}$, followed by a series of reductions at more negative potentials (Figure 9 ). A less well-defined oxidation is observed at potentials greater than $E_{\mathrm{p}}{ }^{\mathrm{a}}-0.29 \mathrm{~V}$ vs $\mathrm{Fc}^{+} / \mathrm{Fc}$. This oxidation is independent of the reduction processes. Bulk reduction of 1 at $-1.40 \mathrm{~V}$ vs saturated calomel electrode (SCE) (ca. $-1.90 \mathrm{~V}$ vs $\mathrm{Fc}^{+} / \mathrm{Fc}$ ) 


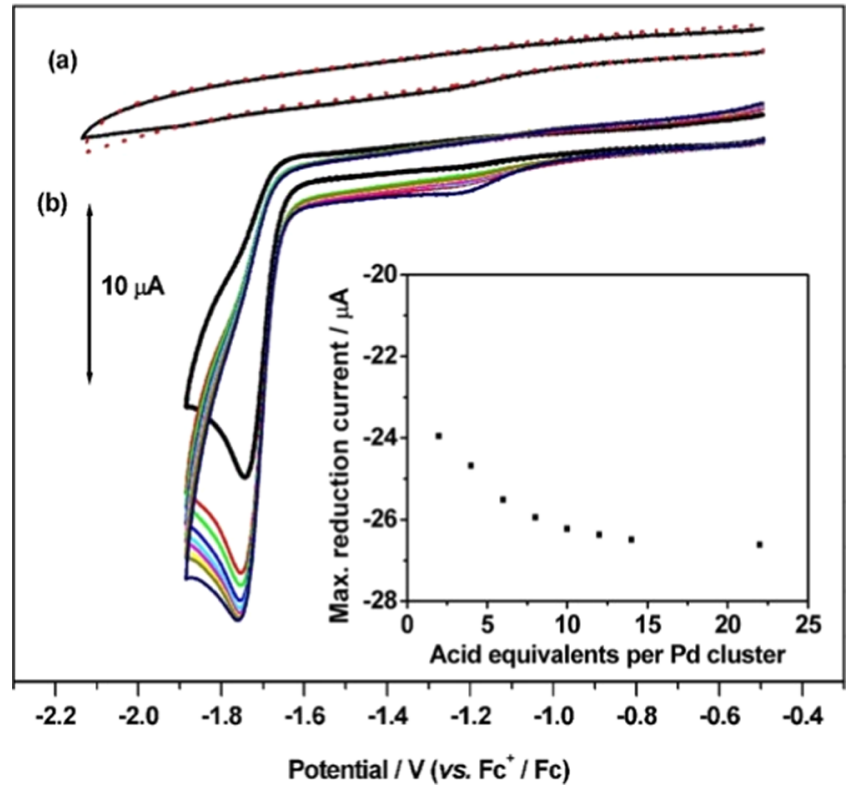

Figure 8. Cyclic voltammetry of (a) DMF containing $\left[{ }^{n} \mathrm{Bu}_{4} \mathrm{~N}\right]\left[\mathrm{BF}_{4}\right]$ $(0.2 \mathrm{M})$ (solid line) and with the addition of acetic acid (dotted line); (b) 1 (bold black line) and the presence of 2-22 equiv of acetic acid. Inset: effect of acid concentration on the reduction current.

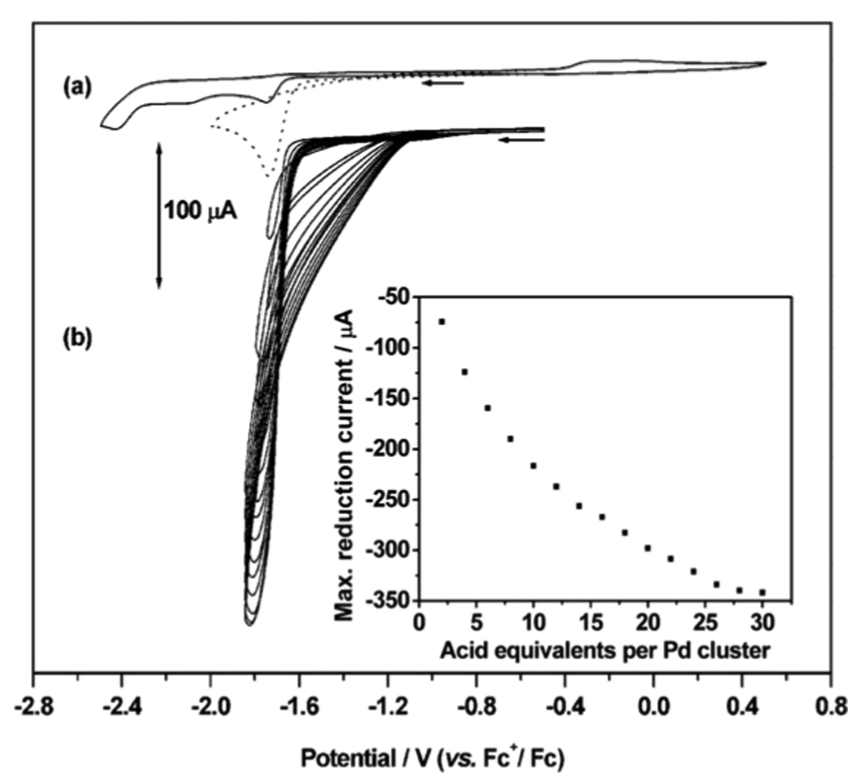

Figure 9. Cyclic voltammetry of (a) 1 in DMF containing $\left[{ }^{n} \mathrm{Bu}_{4} \mathrm{~N}\right]\left[\mathrm{BF}_{4}\right](0.2 \mathrm{M})$ (solid line) and the in the presence of 2 equiv of TFA (dotted line) (b) 1 in the presence of 2-30 equiv of TFA. Inset: effect of acid concentration on the reduction current.

gave a solution color change from yellow to red/brown and the passage of charge corresponding to ca. 1.2 electrons per $\mathrm{Pd}$ center (see the SI, Figure S6). This may indicate that the reduction process at $E_{\mathrm{p}}{ }^{\mathrm{c}}-1.75 \mathrm{~V}$ vs $\mathrm{Fc}^{+} / \mathrm{Fc}$ results in the one electron reduction of each metal center (the additional charge may indicate proton reduction, vide infra). Maintaining an inert atmosphere over the solution, the reduced solution appeared relatively stable.

In the presence of acid, either acetic or TFA, the CV of 1 shows an increase in current for the first reduction process; however, the magnitude of this increase differed significantly with the acid. The increase is small for additions of acetic acid, and there appears little change in either the potential for the onset of reduction or the position of the peak current (Figure 8). By contrast, the addition of TFA to a solution of 1 results in a significant increase in the current obtained compared to the current observed for $\mathbf{1}$ alone (Figure 9). A shift to positive potential for the onset of reduction is also noted with increasing acid concentration, although the position of the peak current remains essentially unchanged. This may be characteristic of protonation at the metal centers of the tiara. The presence of a peak in potentials across the range of acid concentrations employed suggests that the electrode process remains in the regime of diffusion control throughout. However, a plot of $I_{\mathrm{p}}{ }^{\mathrm{c}} /(\mathrm{scan} \text { rate })^{1 / 2}$ vs (scan rate) $)^{1 / 2}$ (where $I_{\mathrm{p}}{ }^{\mathrm{c}}=$ peak cathodic current) for these experiments does not indicate a behavior typical of a catalytic process.

In the presence of TFA, the CV of $\mathbf{1}$ at negative potentials results in a crossing of currents between the forward (reduction) and back (reoxidation) cycles. This is not observed for acetic acid (where currents were significantly lower) and may indicate the deposition of a Pd film or colloid onto the electrode surface upon the reduction of $\mathbf{1}$. Some evidence to support the presence of a heterogeneous deposit on the electrode surface was obtained from an electrode rinsing experiment (see the SI, Figure S7); however, the relatively low currents observed from the coated electrode may suggest that heterogeneous activity is only one, possibly small, contribution to the total current. The bulk reduction of a solution of 1 in the presence of TFA (32 equiv) at $-1.40 \mathrm{~V}$ vs SCE results in the accumulation of sufficient charge to account for tiara reduction and the complete reduction of the acid (assuming the liberation of hydrogen gas). At this applied potential, it is noted that acid reduction occurs in the absence of 1 , although the rate of reduction, given by the gradient of the $Q$ vs $t$ plot (see the SI, Figure S6), appears to be slower. Transmission electron microscopy analysis of the reduced species revealed the presence of discrete nanoparticles, whose palladium composition was confirmed by energy-dispersive Xray spectroscopy (see the Supporting Information).

\section{CONCLUSIONS}

Our studies clearly demonstrate the influence of intramolecular hydrogen-bonding interactions upon the nuclearity of tiara complexes. Whereas the amide-containing ligand, $\mathrm{N}$-acetylcysteamine, used in $\mathbf{1}$ can adopt hydrogen bonds both to other amides within the same tiara and to external molecules, such as water in the crystal structure, the ester containing ligands employed in $\mathbf{2}$ and $\mathbf{3}$ are unable to form such interactions. Thus, the nuclearity of the tiaras formed by $\mathbf{2}$ and 3 is determined by steric factors with both six- and eightmembered tiaras formed in the case of $\mathbf{2}$ and solely eightmembered tiaras formed by 3 . It is interesting to note that when $\mathbf{1}$ is synthesized in the presence of protic solvents, a mixture of tiara nuclearities is observed, indicating that the protic solvent is capable of disrupting the intramolecular hydrogen bonds and thus lessening the influence of the hydrogen bonds in determining nuclearity.

NMR studies indicate that in solution, $\mathbf{1}$ is not in equilibrium with larger tiaras and the smaller size of the sixmembered tiara inhibits the fluxional behavior of the pendent thiolate ligands that is observed for larger, eight-membered, tiaras. ${ }^{8}$ Electrochemical investigations of $\mathbf{1}$ reveal reductive processes with an increase in current upon the addition of acid. The nature of the acid significantly affects the magnitude of 
current observed, and there is some suggestion of the formation of a heterogeneous $\mathrm{Pd}$ species on the electrode surface in the presence of TFA.

Our studies demonstrate that by employing ligand design that encourages intramolecular interactions, the nuclearity of the product tiara can be directed to give exclusively one product. Growing interest in the use of tiaras for the synthesis of nanoparticles ${ }^{14}$ and as hosts for molecular entrapment ${ }^{7,12,13}$ requires the synthesis of complexes with well-determined nuclearity. Our strategy employs a simple approach to affecting the size of the complexes synthesized and avoids mixtures of tiaras that are often encountered. ${ }^{15}$ Ultimately, we believe that by examining the influence of intramolecular interactions, it may be possible to successfully synthesize tiaras of specific sizes through careful ligand design.

\section{EXPERIMENTAL SECTION}

All the reagents were purchased from commercial suppliers and used without further purification. ${ }^{1} \mathrm{H}$ NMR spectra were recorded using a Bruker AV(III)400HD. MALDI-TOF MS spectra were recorded on a Bruker Ultraflex III spectrometer. Elemental analyses were recorded on a CE-440 Elemental Analyzer. For further details of electrochemical experiments and TEM imaging, see the Supporting Information.

Synthesis of 1 . To a solution of $N$-acetylcysteamine (60 $\mu \mathrm{L}, 0.56 \mathrm{mmol}$ ) and $N, N$-diisopropylethylamine $(97 \mu \mathrm{L}, 0.56$ $\mathrm{mmol})$ in THF $(5 \mathrm{~mL})$ was added $\mathrm{PdCl}_{2}(50 \mathrm{mg}, 0.28 \mathrm{mmol})$ and the mixture was stirred for $12 \mathrm{~h}$. The solvent was removed and the solid product was washed with diethyl ether. Orange block crystals of $\mathbf{1}$ were grown by slow diffusion of diethyl ether into a saturated methanol solution $(58 \mathrm{mg}, 61 \%)$ and used for subsequent studies. ${ }^{1} \mathrm{H}$ NMR (400 MHz, MeOD) $\delta$ $3.57\left(\mathrm{t}, 12 \mathrm{H}, \beta-\mathrm{CH}_{2}\right), 3.44\left(\mathrm{t}, 12 \mathrm{H}, \beta-\mathrm{CH}_{2}\right), 2.67(\mathrm{t}, 12 \mathrm{H}, \alpha-$ $\left.\mathrm{CH}_{2}\right), 2.58\left(\mathrm{t}, 12 \mathrm{H}, \alpha-\mathrm{CH}_{2}\right), 2.02\left(\mathrm{~s}, 18 \mathrm{H}, \mathrm{CH}_{3}\right), 1.98(\mathrm{~s}, 18 \mathrm{H}$, $\left.\mathrm{CH}_{3}\right)$. MS MALDI (+) (MeOH, DCTB/MeCN) $m / z 2077.9$ $[\mathrm{M}+\mathrm{Na}]^{+}$. Analytically pure samples were recrystallized from $\mathrm{MeCN}$. Anal. calcd for $\mathrm{Pd}_{6} \mathrm{~S}_{12} \mathrm{~N}_{12} \mathrm{O}_{12} \mathrm{C}_{48} \mathrm{H}_{96} \cdot \mathrm{CH}_{3} \mathrm{CN}$ : C, 28.62; H, 4.58; N, 8.68. Found: C, 29.18; H, 4.79; N, 8.46.

Synthesis of 2. To a solution of 2-mercaptoethyl acetate $(61 \mu \mathrm{L}, 0.56 \mathrm{mmol})$ and dimethylaminopyridine $(68 \mathrm{mg}, 0.56$ $\mathrm{mmol})$ in THF $(5 \mathrm{~mL})$ was added $\mathrm{PdCl}_{2}(50 \mathrm{mg}, 0.28 \mathrm{mmol})$ and the resulting orange suspension was stirred for $18 \mathrm{~h}$. The solvent was removed and the solid dissolved in $\mathrm{CH}_{2} \mathrm{Cl}_{2}$, washed with $\mathrm{NaOH}(0.1 \mathrm{M})$ and brine and dried over magnesium sulfate $(63 \mathrm{mg}, 65 \%)$. Single crystals were obtained following slow evaporation of a saturated $\mathrm{CHCl}_{3}$ solution and used for subsequent studies. ${ }^{1} \mathrm{H}$ NMR $\left(400 \mathrm{MHz} \mathrm{CDCl}_{3}\right) \delta$ $4.39\left(\mathrm{t}, 12 \mathrm{H}, \beta-\mathrm{CH}_{2}\right), 4.29\left(\mathrm{t}, 12 \mathrm{H}, \beta-\mathrm{CH}_{2}\right), 2.78(\mathrm{t}, 12 \mathrm{H}, \alpha-$ $\left.\mathrm{CH}_{2}\right), 2.66\left(\mathrm{t}, 12 \mathrm{H}, \alpha-\mathrm{CH}_{2}\right), 2.14\left(\mathrm{~s}, 18 \mathrm{H}, \mathrm{CH}_{3}\right), 2.09(\mathrm{~s}, 18 \mathrm{H}$, $\left.\mathrm{CH}_{3}\right)$. MS MALDI (+) $\left(\mathrm{CHCl}_{3}, \mathrm{DCTB} / \mathrm{MeCN}\right) \mathrm{m} / z 2091.9$ $[\mathrm{M}+\mathrm{Na}]^{+}$. Anal. calcd for $\mathrm{Pd}_{8} \mathrm{~S}_{16} \mathrm{O}_{32} \mathrm{C}_{64} \mathrm{H}_{112}: \mathrm{C}, 27.87 ; \mathrm{H}$, 4.09; N, 0. Found: C, 27.72; H, 4.06; N, 0 .

Synthesis of 3. To a solution of ethyl thioglycolate $(61 \mu \mathrm{L}$, $0.56 \mathrm{mmol})$ and dimethylaminopyridine $(68 \mathrm{mg}, 0.56 \mathrm{mmol})$ in THF $(5 \mathrm{~mL})$ was added $\mathrm{PdCl}_{2}(50 \mathrm{mg}, 0.28 \mathrm{mmol})$ and the mixture stirred for $6 \mathrm{~h}$. The solvent was removed and the solid dissolved in $\mathrm{CH}_{2} \mathrm{Cl}_{2}$, washed with $\mathrm{NaOH}(0.1 \mathrm{M})$ and brine, and dried over magnesium sulfate. Following the evaporation of the solvent, the orange solid was recrystallized from isopropanol (56 mg, 58\%) and used for subsequent studies. ${ }^{1} \mathrm{H}$ NMR (400 MHz, $\left.\mathrm{CDCl}_{3}\right) \delta 4.44\left(\mathrm{q}, 12 \mathrm{H}, \beta-\mathrm{CH}_{2}\right), 4.24(\mathrm{q}$, $\left.12 \mathrm{H}, \beta-\mathrm{CH}_{2}\right), 3.39\left(\mathrm{~s}, 12 \mathrm{H}, \alpha-\mathrm{CH}_{2}\right), 3.27\left(\mathrm{~s}, 12 \mathrm{H}, \alpha-\mathrm{CH}_{2}\right)$, $1.56\left(\mathrm{t}, 18 \mathrm{H}, \mathrm{CH}_{3}\right), 1.34\left(\mathrm{t}, 18 \mathrm{H}, \mathrm{CH}_{3}\right)$. MS MALDI $(+)$
$\left(\mathrm{CHCl}_{3}, \mathrm{DCTB} / \mathrm{MeCN}\right) m / z 2783.0[\mathrm{M}+\mathrm{Na}]^{+}, 2799.0[\mathrm{M}+$ $\mathrm{K}]^{+}$. Anal. calcd for $\mathrm{Pd}_{8} \mathrm{~S}_{16} \mathrm{O}_{32} \mathrm{C}_{64} \mathrm{H}_{112}: \mathrm{C}, 27.87 ; \mathrm{H}, 4.09 ; \mathrm{N}, 0$. Found: C, 27.68; H, 3.91; N, 0 .

Crystal data for 1: $\mathrm{C}_{49} \mathrm{H}_{105} \mathrm{~N}_{12} \mathrm{O}_{17} \mathrm{Pd}_{6} \mathrm{~S}_{12}$. Triclinic, space group $P \overline{1}, a=12.20826(12), b=12.65614(11), c=$ 14.81683(10) A, $\alpha=93.1977(6), \beta=110.0979(8), \gamma=$ $108.7469(8)^{\circ}, V=2000.00(3) \AA^{3}, Z=1, D_{\text {calc }}=1.791 \mathrm{~g} \mathrm{~cm}^{-3}$, $\mu=14.128 \mathrm{~mm}^{-1}, F(000)=1087$. A total of 124159 reflections were collected, of which 8023 were unique, with $R_{\text {int }}$ $=0.040$. Final $R_{1}\left(w R_{2}\right)=0.0169(0.0431)$ with GOF $=1.06$.

Crystal data for 2: $\mathrm{C}_{48} \mathrm{H}_{84} \mathrm{O}_{24} \mathrm{Pd}_{6} \mathrm{~S}_{12}$. Triclinic, space group $P \overline{1}, a=11.6640(4), b=12.0973(4), c=13.5387(5) \AA, \alpha$ $=74.597(3), \beta=87.925(3), \gamma=85.810(3)^{\circ}, V=1836.53(11)$ $\AA^{3}, Z=1, D_{\text {calc }}=1.870 \mathrm{~g} \mathrm{~cm}^{-3}, \mu=15.383 \mathrm{~mm}^{-1}, F(000)=$ 1032. A total of 13441 reflections were collected, of which 7197 were unique, with $R_{\text {int }}=0.023$. Final $R_{1}\left(w R_{2}\right)=0.0344$ (0.0951) with GOF $=1.05$.

Crystal data for 3: $\mathrm{C}_{64} \mathrm{H}_{120} \mathrm{O}_{32.5} \mathrm{Pd}_{8} \mathrm{~S}_{16}$. Monoclinic, space group $C 2 / c, a=26.3460(6), b=26.3625(5), c=31.9593(8)$ $\AA$, $\beta=113.960(3)^{\circ}, V=20284.4(8) \AA^{3}, Z=8, D_{\text {calc }}=1.817 \mathrm{~g}$ $\mathrm{cm}^{-3}, \mu=14.862 \mathrm{~mm}^{-1}, F(000)=11104$. A total of 20407 reflections were collected, of which 18584 were unique, with $R_{\text {int }}=0.049$. Final $R_{1}\left(w R_{2}\right)=0.0669(0.1971)$ with $\mathrm{GOF}=$ 1.03 .

\section{ASSOCIATED CONTENT}

\section{S Supporting Information}

The Supporting Information is available free of charge on the ACS Publications website at DOI: 10.1021/acsomega.8b01133.

${ }^{1} \mathrm{H}$ NMR spectra and electrochemical data; CCDC 1528752 (1), CCDC 1528753 (2), and CCDC 1528754 (3) (PDF)

\section{AUTHOR INFORMATION}

\section{Corresponding Author}

*E-mail: Neil.Champness@nottingham.ac.uk. Phone: +44 (0) 1159513505.

ORCID ${ }^{\circ}$

William Lewis: 0000-0001-7103-6981

Neil R. Champness: 0000-0003-2970-1487

Notes

The authors declare no competing financial interest.

\section{ACKNOWLEDGMENTS}

This work was supported by the Engineering and Physical Sciences Research Council (EP/K01773X/1) and the Leverhulme Trust (RPG-2014-317). H.J.M. also acknowledged EPSRC funding via a doctoral training grant; N.R.C. gratefully acknowledges a Royal Society Wolfson Merit Award.

\section{REFERENCES}

(1) Zhang, C.; Matsumoto, T.; Samoc, M.; Petrie, S.; Meng, S.; Corkery, T. C.; Stranger, R.; Zhang, J.; Humphrey, M. G.; Tatsumi, K. Dodecanuclear-Ellipse and Decanuclear-Wheel Nickel(II) Thiolato Clusters with Efficient Femtosecond Nonlinear Absorption. Angew. Chem., Int. Ed. 2010, 49, 4209-4212.

(2) Tan, C.; Jin, M.; Ma, X.; Zhu, Q.; Huang, Y.; Wang, Y.; Hu, S.; Shen, T.; Wu, X. In situ synthesis of nickel tiara-like clusters with two different thiolate bridges. Dalton Trans. 2012, 41, 8472-8476.

(3) Chen, Q.; Liu, S.; Zubieta, J. Formation of an Oxalate-filled Cavity in a Reduced Cyclic Octanuclear Polyoxomolybdate [(n- 
$\left.\left.\mathrm{C}_{4} \mathrm{H}_{9}\right)_{4} \mathrm{~N}\right]_{2}\left[\mathrm{Mo}_{8} \mathrm{O}_{16}\left(\mathrm{OCH}_{3}\right)_{8}\left(\mathrm{C}_{2} \mathrm{O}_{4}\right)\right]$ formed from $\alpha$ - $[(n-$ $\left.\left.\mathrm{C}_{4} \mathrm{H}_{9}\right)_{4} \mathrm{~N}\right]_{4}\left[\mathrm{Mo}_{8} \mathrm{O}_{26}\right]$ and Rhodizonic Acid. Angew. Chem., Int. Ed. Engl. 1988, 27, 1724-1725.

(4) Chen, Q.; Liu, S.; Zubieta, J. A cyclic octanuclear polyoxoalkoxy vanadate(IV) with an oxalate-binding cavity, [(n$\left.\left.\mathrm{C}_{4} \mathrm{H}_{9}\right)_{4} \mathrm{~N}\right]_{2}\left[\mathrm{~V}_{8} \mathrm{O}_{8}\left(\mathrm{OCH}_{3}\right)_{16}\left(\mathrm{C}_{2} \mathrm{O}_{4}\right)\right]$. Structural comparison with the analogous polymolybdates(V) complex [(n$\left.\left.\mathrm{C}_{4} \mathrm{H}_{9}\right)_{4} \mathrm{~N}\right]_{2}\left[\mathrm{Mo}_{8} \mathrm{O}_{16}\left(\mathrm{OC}_{2} \mathrm{H}_{5}\right)_{8}\left(\mathrm{C}_{2} \mathrm{O}_{4}\right)\right]$. Inorg. Chem. 1989, 28, $4433-4434$.

(5) Wang, J.; Jian, F.; Huang, B.; Bai, Z. Two molecular wheels 12MC-6 complexes: Synthesis, structure and magnetic property of $\left[\mathrm{Co}\left(\mu_{2}-\mathrm{SEt}\right)_{2}\right]_{6}$ and $\left[\mathrm{Fe}\left(\mu_{2}-\mathrm{SEt}\right)_{2}\right]_{6}$. J. Solid State Chem. 2013, 204, 272-277.

(6) Nobusada, K.; Yamaki, T. Electronic Properties of PalladiumThiolate Complexes with Tiara-like Structures. J. Phys. Chem. A 2004, 108, 1813-1817.

(7) Dance, I. G.; Scudder, M. L.; Secomb, R. c-Ni $\mathrm{Ni}_{8}\left(\mathrm{SCH}_{2} \mathrm{COOEt}\right)_{16}$, a receptive octagonal toroid. Inorg. Chem. 1985, 24, 1201-1208.

(8) Yamashina, Y.; Kataoka, Y.; Ura, Y. Tiara-like Octanuclear Palladium(II) and Platinum(II) Thiolates and Their Inclusion Complexes with Dihalo- or Iodoalkanes. Inorg. Chem. 2014, 53, 3558-3567.

(9) Alemany, P.; Hoffmann, R. Toroidal nickel thiolates: structure and bonding. J. Am. Chem. Soc. 1993, 115, 8290-8297.

(10) Kagalwala, H. N.; Gottlieb, E.; Li, G.; Li, T.; Jin, R.; Bernhard, S. Photocatalytic Hydrogen Generation System Using a NickelThiolate Hexameric Cluster. Inorg. Chem. 2013, 52, 9094-9101.

(11) Zhang, W.; Hong, J.; Zheng, J.; Huang, Z.; Zhou, J.; Xu, R. Nickel-Thiolate Complex Catalyst Assembled in One Step in Water for Solar $\mathrm{H}_{2}$ Production. J. Am. Chem. Soc. 2011, 133, 20680-20683.

(12) Zhang, C.; Takada, S.; Kölzer, M.; Matsumoto, T.; Tatsumi, K. Nickel(II) Thiolate Complexes with a Flexible cyclo- $\left\{\mathrm{Ni}_{10} \mathrm{~S}_{20}\right\}$ Framework. Angew. Chem., Int. Ed. 2006, 45, 3768-3772.

(13) Ivanov, S. A.; Kozee, M. A.; Merrill, W. A.; Agarwal, S.; Dahl, L. F. Cyclo- $\left[\mathrm{Ni}\left(\mu_{2}-\mathrm{SPh}\right)_{2}\right]_{9}$ and cyclo- $\left[\mathrm{Ni}\left(\mu_{2}-\mathrm{SPh}\right)_{2}\right]_{11}$ : new oligomeric types of toroidal nickel(II) thiolates containing geometrically unprecedented 9- and 11-membered ring systems. J. Chem. Soc., Dalton Trans. 2002, 4105-4115.

(14) Yang, Z.; Smetana, A. B.; Sorensen, C. M.; Klabunde, K. J. Synthesis and Characterization of a New Tiara $\mathrm{Pd}(\mathrm{II})$ Thiolate Complex, $\left[\mathrm{Pd}\left(\mathrm{SC}_{12} \mathrm{H}_{25}\right)_{2}\right]_{6}$, and Its Solution-Phase Thermolysis to Prepare Nearly Monodisperse Palladium Sulfide Nanoparticles. Inorg. Chem. 2007, 46, 2427-2431.

(15) Chen, J.; Liu, L.; Weng, L.; Lin, Y.; Liao, L.; Wang, C.; Yang, J.; $\mathrm{Wu}, \mathrm{Z}$. Synthesis and Properties Evolution of a Family of Tiara-like Phenylethanethiolated Palladium Nanoclusters. Sci. Rep. 2015, 5, No. 16628.

(16) Tan, C.; Jin, M.; Zhang, H.; Hu, S.; Sheng, T.; Wu, X. Penta and hexanuclear nickel tiara-like clusters with two different thiolate bridges. CrystEngComm 2015, 17, 5110-5115.

(17) Evans, R.; Deng, Z.; Rogerson, A. K.; McLachlan, A. S.; Richards, J. J.; Nilsson, M.; Morris, G. A. Quantitative Interpretation of Diffusion-Ordered NMR Spectra: Can We Rationalize Small Molecule Diffusion Coefficients? Angew. Chem., Int. Ed. 2013, 52, 3199-3202. 